\title{
LA FORMACION DEL DIRECTIVO EMPRESARIAL COMO VARIABLE ESTRATEGICA DE CAMBIO
}

\author{
Francisco Parra Luna
}

Universidad Complutense de Madrid

\section{RESUMEN}

Desde una perspectiva crítica, se pretende señalar que relevantes teorías organizacionales no han sido todavía incorporadas a los curricula básicos de los directivos empresariales, así como la pervivencia de la tradicional desconexión universidad-empresa. Entre los enfoques teóricos que formarían parte de esta "distancia conceptual» se encontrarían el concepto axiológico de empresa (productora, exclusivante, de sistemas de valores); el cálculo de la eficiencia empresarial (o relación entre los valores producidos y medios empleados); el concepto de entorno al que debe adaptarse la empresa (análisis de los cambios sociales, económicos, culturales y otros); la concepción de la empresa como «sistema suma no cero" (lo que potenciaría o daría lugar a procesos de negociación sinérgicos versus homeostáticos) y, por último, el diseño de un concepto de formación como correlato del plan estratégico de la empresa en respuesta a los desafíos del entorno. Se apunta finalmente un proceso formativo al nivel global de empresa, que consta de ocho fases, llamado «Plan Estratégico-Participativo de Formación».

\section{INTRODUCCION}

El presente trabajo está asumido desde una perspectiva crítica. Pretende señalar la insuficiente atención que por parte de los responsables empresariales se presta a algunas teorías recientemente establecidas, o al menos suficientemente elaboradas, al mismo tiempo que subsistiría una cierta despreocupación de los teóricos por hacerlas llegar a los empresarios. Se trata de un problema de

\section{Reis}


incomunicación mutua que supondría una rémora para la formación de ambos colectivos y que presenta su correlato en la insuficiente conexión UniversidadEmpresa, medio idóneo para una formación teórico-práctica interactiva. En general, la necesidad de formación viene siendo insistentemente denunciada, tanto desde los ámbitos teóricos (p. ej., Rosow, 1990; Coopnet, 1995; Sloman, 1994) como de los políticos y empresariales —UNESCO, OIT (ILO), Plan europeo FORCEN, CEOE, etc.- . Autores como Tofler, Drucker y Bell vienen sosteniendo que los problemas de nuestra civilización son principalmente problemas de insuficiente preparación teórica y práctica para hacer frente a los desafíos de un mundo crecientemente superpoblado, tecnificado y complejo. En los más recientes foros que se vienen celebrando sobre la educación en el siglo XXI se pone así de manifiesto: "La Utopía educativa ha ido creciendo en factibilidad y podemos esperar grandes transformaciones y cambios. El de mayor magnitud será el enfoque de la educación permanente para toda la vida que afectará al sistema laboral y a las pautas de vida individual» (Malitza, 1996).

Desde la perspectiva crítica asumida, y si ésta es una necesidad generalizada válida para la totalidad de las instituciones que entraman la complejidad social del planeta, aún lo es más para esa institución llamada empresa que se tiende a contemplar hoy como la célula socioeconómica fundamental de la sociedad moderna. Y muy en particular la empresa privada, la institución que se ve forzada a obtener una rentabilidad mínima del capital empleado en medio de una turbulenta constelación de empresas competidoras que le disputan el mercado con el celo propio de quienes les va en ello la supervivencia, o, para ser más precisos, en los términos cuasimilitares de lucha, estrategia, combate, objetivo o movilización (Plessis, 1984). Circunscribiéndonos, pues, al ámbito de la empresa privada, numerosos trabajos vienen contrastando las enormes y cambiantes necesidades de formación que afectan al personal directivo de las empresas. Una empresa no resuelve sus problemas sólo porque generalice o institucionalice la formación continua del personal en los escalones medios o bajos, como cuando de la mecanografía clásica se pasa al tratamiento de texto en el ordenador, sino, sobre todo, cuando los que han de tomar decisiones estratégicas evalúan correctamente las ventajas e inconvenientes de las alternativas posibles. Resulta, pues, prioritario y esencial comenzar por inventariar las necesidades de formación de los máximos responsables de las empresas, comenzando por la propia idea o concepción que se tiene de la empresa. Necesidades, pues, que ya no se limitan a la mera repetición de definiciones clásicas de lo que fue la empresa, sino de lo que está siendo hoy y de lo que será muy probablemente mañana. El quid de la cuestión reside, como veremos, en el propio concepto empresarial del empresario. Aunque se suele diferenciar entre empresario (el que diseña negocios), inversor (el que pone el dinero) y gestor (el que gestiona), vamos a considerar «empresario» al máximo gestor de la entidad, posea o no capital en la misma, proyecte o no nuevas ideas empresariales. Ese gestor que se convierte en la variable estratégica del cambio empre- 
sarial por mor de sus facultades de acción e influencia sobre otras variables determinantes como la comercial, financiera, tecnológica, organizacional, etc. Aspectos todos que pasan por, o dependen del, papel que acierte a jugar el máximo responsable de la empresa. Tal es la posición central de la gestión directiva, que incluso resulta conveniente formalizar en la manera matemática la relación existente para decir que el cambio empresarial es una función de calidad de la gestión y ésta a su vez depende de la formación del gestor. El cambio en la empresa se presentaría así como una función de función donde la variable explicativa principal recaería en la formación teórico-técnica del responsable empresarial.

Determinado, pues, el sujeto de la formación, que llamaré simplemente $D E$ o Directivo empresarial, el objetivo del presente trabajo va a consistir en señalar y desarrollar esquemáticamente algunos de los conceptos básicos que están haciendo defecto, o incluso están ausentes, de los programas formativos para $D E$. Dejando aparte la enorme cantidad y variedad de cursos, seminarios y materias que se imparten continuamente en el mercado para $D E$, así como los propios deseos de formación de los interesados expresados en diferentes encuestas, el presente análisis se va a centrar en algunas nuevas dimensiones, a veces más implícita que explícitamente tratadas en la literatura especializada, pero que revierten en una serie de desarrollos teóricos que se pueden resumir en tres campos: primero, trabajos centrados en nuevos avances del concepto y definición de sistema social con repercusiones en el concepto de empresa (Ackoff, Beer, Drucker, Checkland, Campbell, Giddens...); segundo, trabajos centrados en el concepto de Entorno empresarial (Deming, Jungk, Toffler, Bell, Naisbitt, Lazlo...); y tercero, trabajos centrados en la función de formación en la empresa. (Kubr y Prokopenko, Nadler, Contantinidis, Coopnet, Rayner y Fisher, Belasco...).

De una lectura detenida y compulsada de esta literatura destacan unas necesidades concretas de formación para $D E$, que pueden enunciarse como un conjunto de hipótesis formativas resumibles en las cinco siguientes: 1 . Necesidad de concebir la empresa como productora, únicamente, de un sistema de valores especializado, lo que obliga a centrarse más en el aspecto humano de la misma y a comprender que la variable «organización» es, o suele ser, el factor de mayor poder explicativo de la empresa. 2. De coómo definir operacionalmente el concepto de Eficiencia empresarial, obligado norte y guía de todo $D E$. 3. De cómo calibrar los cambios del Entorno empresarial y lograr la más adecuada interacción dinámica con el mismo. 4. De cómo concebir la empresa en tanto que sistema "suma no cero", autopoiético o automultiplicativo y de cómo integrar al personal a través de su participación en la gestión con los fines últimos empresariales. 5. De cómo implementar planes estratégico-participados de formación susceptibles tanto de mejorar la rentabilidad de la empresa como de preparar a sus $D E$ para el futuro. Cinco necesidades de formación todavía más ignoradas que asumidas, pero de una importancia decisiva para el desarrollo organizacional y empresarial. A especificar brevemente los nuevos conceptos 
que responden a estas necesidades se dirigen las páginas siguientes. Con una hipótesis de trabajo central: si los $D E$ no fueran conscientes de estas lagunas formativas, las empresas bajo su responsabilidad podrían encontrar dificultades que probablemente resultarían proporcionales al grado de inaplicación de dichos conceptos.

\section{HACIA UN CONCEPTO AXIOLOGICO DE EMPRESA}

Definitivamente arrumbadas quedaron las viejas definiciones de empresa en tanto que «conjunciones de naturaleza, trabajo y capital con el fin de obtener un beneficio». Incluso resultan inapropiadas definiciones como la de Heller (1965), aunque ésta explicite bastante bien sus rasgos característicos, a saber: «a) la existencia de un patrimonio que permite al empresario asumir el riesgo de la producción; b) la combinación con otros factores de la producción como el factor trabajo en términos económicos; c) la distribución entre los sujetos intervinientes como trabajadores y capitalistas; $d$ ) el objetivo empresarial en tanto que venta de bienes y servicios para satisfacer necesidades de clientes; y $e$ ) la búsqueda del máximo beneficio posible». La empresa es, sin embargo, todo eso y algo más, ya que se trata esencialmente de una entidad productiva de sistemas complejos de valores. La empresa ya no es sólo un proceso de transformación de materias primas y de horas de trabajo en productos terminados o servicios prestados con la intención de ganar dinero, sino una producción sistemática e inevitable, y más bien invisible, de valores culturales.

La vieja idea de empresa mercantil arrastra una concepción economicista demasiado centrada en una oferta de bienes/servicios a cambio de beneficio, cuando en realidad la empresa no podría dejar, aunque quisiera, de producir Valores en respuesta a las necesidades concretas de los individuos que la forman (no sólo de sus clientes, sino de todos los que componen sus ámbitos sociales). La empresa moderna se concebiría así como un conjunto interrelacionado de personas carentes, donde ni la naturaleza (la tierra), ni el capital (financiación), ni siquiera los beneficios alcanzados pasarían de ser ahora meros instrumentos al servicio de dichas personas que no tratan sino de satisfacer sus necesidades, ya sean básicas o superficiales, naturales o artificiales. Desde esta perspectiva humanístico-axiológica, no encontraríamos actividad humana que no produjera, de alguna u otra forma, valores, puesto que sólo valores es lo que puede ser objeto de posesión o deseo por parte de personas, y resultaría difícil concebir actividad humana alguna que no persiguiera valores, ya consista en ganar dinero, divertirse, formar una familia o convertirse en anacoreta. Todo lo que rodea la sociedad humana está determinado por y para los valores perseguidos. De ahí la cantidad de trabajos que vienen apareciendo sobre los valores y la cultura empresarial y organizacional (p. ej., Van Gigh, 1978; Levitt, 1988; Schein, 1988; Alberoni, 1994; Garmendia, 1994; Hall, 1994...). Llegado este momento resulta preciso referirse al modelo utilizado en varios trabajos anteriores como 
Patrón Referencial de Valores (en adelante, PRV), que comprende los diez siguientes: Salud (S), Seguridad (Se), Riqueza Material (RM), Conocimiento (C), Libertad (L), Justicia (J), Conservación de la Naturaleza (CN), Calidad de las Actividades (CA), Prestigio (P) y Poder (Po).

Si cualquier actividad humana se atiene a dicho Patrón, ¿por qué diferenciar entre sistemas sociales, organizaciones y empresas, tres conceptos que, junto al de institución, sólo persiguen realizar sistemas de valores? La respuesta resulta tan capital como simple: la diferencia esencial entre un sistema social y una organización reside en que ésta es siempre artificial; y la diferencia entre una organización y una empresa reside en que la última está especializada en el valor Riqueza Material (RM), o sea, obtener rentabilidad del capital empleado. Así, la empresa se caracteriza por acentuar el valor Riqueza Material a costa muchas veces del valor Conservación de la Naturaleza (como cuando explota recursos naturales insustituibles o deteriora el ambiente con vertidos contaminantes), mientras que organizaciones (o instituciones) como la Iglesia o las FF.AA. persiguen el valor Seguridad, un Instituto de Investigación el valor Conocimiento o un club cultural la Calidad de las Actividades. Queda claro que entre los conceptos de Sistema Social $(S)$, Organización $(O)$ y Empresa $(E)$ existe una relación de inclusión que se formalizaría como: $E \subset S, E \subset O$ y $O \subset S$. En otras palabras, todas las empresas son sistemas y organizaciones y todas las organizaciones a su vez sistemas sociales, pero no lo contrario, ya que la relación transitiva no se cumple. No sobra acentuar que aunque la empresa es una organización especializada en el valor $R M$ (obtener rentabilidad económica), no por ello está exenta de realizar los otros valores del Patrón Referencial citado. Existe, además, una hipótesis bien fundamentada ya por ciertas experiencias que demuestran que cuando la empresa deja de dirigirse de una forma demasiado directa hacia el objeto «beneficio económico", para pasar a través del resto de los valores, principalmente el de Calidad de las Actividades (participación en la gestión empresarial), consigue mayores beneficios económicos. Esta hipótesis puede convertirse en uno de los principales desafíos de la moderna sociología de la empresa: demostrar la relación directa entre la variable participación e integración del personal en la empresa (CA) y la variable beneficios económicos (RM). En efecto, si $R M=f(C A)$ y si $C A=f(S, S e, L, J \ldots)$, entonces queda evidenciado que la empresa, aunque sólo buscara rentabilidad económica, habría de maximizar la realización de la totalidad de los valores del $P R V$. La empresa podría quedar entonces definida como el intento sistemático de maximizar el valor $R M$ a través de la maximización del resto de los valores del PRV y ello a partir de la utilización de unos medios limitados, normalmente financieros. De donde cabría enunciar el primero de los que llamaré «desafíos formativos»: ningún empresario debería desconocer que lo que produce es, únicamente, un complejo y especializado sistema de valores, lo que implicaría centrar su atención en las personas que componen la empresa. 


\section{LA MEDIDA DE LA EFICIENCIA EMPRESARIAL}

Esta introducción formalizada al nuevo concepto de empresa permite avanzar hacia la medida de su eficiencia o performance. Si existe un segundo principio que todo $D E$ deba conocer es cómo percibir, calibrar o medir la eficiencia o performance global de la empresa que dirige. Le va en ello, lógicamente, su reputación/profesionalidad, ya que el término eficiencia significa hasta qué punto la empresa cumple sus objetivos programados. Se sabe, además, que una empresa es eficiente cuando su organización es eficiente. En este sentido, la empresa no es sino pura organización o combinación de elementos personales y materiales con vistas a producir el mejor sistema de valores posible. De ahí que el concepto de eficiencia empresarial resulte sinónimo de eficiencia organizacional y que su cálculo responda con exactitud a las mismas reglas metodológicas, residiendo la diferencia entre ambos en que el número y peso de los indicadores que representen el valor $R M$ en el concepto de Eficiencia Empresarial serán muy superiores a los que se empleen en el concepto de eficiencia organizacional. Siendo, pues, idénticos los aspectos formales, podemos comenzar por destacar la Relevancia de dicho concepto. Recordemos que las Organizaciones fueron definidas por Max Weber como «un sistema de actividades humanas continuamente dirigidas hacia un fin específico». Esta idea es tan básica y general que se ha mantenido en casi todas las definiciones posteriores. Por ejemplo, Parsons (1960) las define como «unidades sociales o agrupaciones humanas deliberadamente construidas y reconstruidas para perseguir fines específicos». Sabemos, pues, que las organizaciones existen sólo porque buscan realizar ciertos objetivos. Mas, como se ha dicho antes, éstos son extremadamente variados. Así, las empresas buscan un beneficio al capital invertido, las burocracias el funcionamiento del aparato judicial y político, las escuelas y universidades la divulgación del conocimiento, las iglesias la divulgación de sus creencias, las asociaciones deportivas el mejoramiento físico personal o el éxito competitivo, los hospitales y las clínicas la curación de sus enfermos, etc. Se constata así que los fines de las organizaciones representan su característica esencial o su razón de ser. El estudio de estos fines es, en consecuencia, sumamente interesante tanto del punto de vista teórico como práctico. No es de extrañar que una gran parte de la literatura científica sobre organizaciones se haya centrado sobre los fines, objetivos o goals de las mismas. Por ejemplo, R. Mayntz (1967), en su obra Sociología de la Organización, le dedica el capítulo cuarto, así como diversos trabajos de Ch. Perrow (1961, 1963 y 1968), exclusivamente consagrados al tema de los goals de la organización. Van Gigh (1978), y en particular los trabajos desarrollados por el enfoque praxiológico (Lee et al., 1992; Gasparski et al., 1996), acentúan fuertemente la importancia de los objetivos organizacionales. Recientemente, también Seoane (1994), al definir la organización, enfatiza su propósito, sus metas y su finalidad; y Bradley (1995) sostiene la necesidad de informar a accionistas, empleados, proveedores y clientes de la eficiencia de la 
empresa mediante una selección adecuada de indicadores cuantitativos objetivos y subjetivos.

En realidad, la explicación adecuada de los fines resulta imprescindible no sólo para comprender la organización, sino para definir y medir uno de los conceptos más importantes que pueden manejar hoy las ciencias sociales: el de PERFORMANCE SOCIAL, vocablo que en español viene a significar algo aproximado a «rendimiento", "eficacia», «eficiencia», «efectividad», etc. Podría decirse en principio que toda organización social se justifica y se legitima solamente en la medida que registra una performance adecuada, es decir, que cumple los fines para los que se creó. En general, un segundo principio puede también establecerse: TODA ORGANIZACION JUSTIFICA SU EXISTENCIA EN UN GRADO DIRECTAMENTE PROPORCIONAL A SU PERFOR$M A N C E$. De ahí que la moderna sociología de las organizaciones tienda a considerar el concepto de performance, más o menos explícitamente, como uno de sus instrumentos básicos (ver, p. ej., los trabajos del Center for Effective Organizations, CA, EE.UU.). Su hipótesis es que si un grupo social estructurado hacia un fin no cumple sus objetivos en la forma esperada, las causas principales habría que buscarlas en variables sociológicas por excelencia: su organización interna, la organización social circundante más próxima, la organización sociopolítica del país, etc. (March y Simon, 1981; Perrow, 1991). Pero si el concepto de «Eficiencia» resulta central en la percepción de la organización, definir dicha eficiencia, y más aún medirla, no parece posible sin el recurso a un enfoque globalista o sistémico. En efecto, ¿cómo podría hablarse de EFICIENCIA ORGANIZACIONAL, forzosamente referida al conjunto de la organización, sin pasar por la totalidad de funciones que ésta acomete $(Y)$ y de la totalidad de gastos o medios empleados para ello $(X)$ ? Definir, como haremos más adelante, la Eficiencia Organizacional por el cociente $Y / X$ exige aplicar rigurosamente principios derivados de la Teoría de Sistemas donde las implicaciones lógicas propias del enfoque sociosistémico de la organización, a saber: Dimensionalización Ontológica, Principios Metodológicos, Operaciones Epistemológicas, Procesos Funcionales y Fases Operativas (Parra Luna, 1983, p.154), han de ser forzosamente tenidos en cuenta, so pena de no poder delimitar un concepto tan complejo como el de «Eficiencia Organizacional». A pesar de la creciente importancia del concepto, lo que en mi conocimiento no se ha intentado todavía es una definición de performance capaz de adaptarse a cualquier tipo de organización. Ello posiblemente sea debido a que una buena parte de la literatura sociológica sobre organizaciones no aplica, al menos de una manera explícita y dentro de sus principios fundamentales, enfoques sistémicos o globalistas, lo que conllevaría ciertas operaciones epistemológicas tales como SOCIOLOGIZACION (contemplar al sistema social desde la óptica de la población que lo compone), RECURSIFICACION (descripción de los medios disponibles o potenciales), JERARQUIZACION (explicitación de la pirámide de posiciones, roles y poderes sociales que inspiran su funcionamiento), ADAPTACION (necesidad de equilibrarse axiológi- 
camente con su entorno), RETROALIMENTACION (descontado lo que se queda en el entorno, todo lo que sale del sistema vuelve a entrar en el mismo) y CONTROL CIBERNETICO (minimización de las diferencias Previsto-Realizado).

Mediante el empleo de estos conceptos, el puente teórico entre la Sociología de las Organizaciones y la Eficiencia Organizacional quedaría aceptablemente tendido, así como la posibilidad de percibir la organización en sus características más relevantes. Si estos conceptos se aplicaran se daría, ciertamente, un paso fundamental hacia la comprensión, medición y comparación espacio-temporal de las organizaciones.

De una forma exploratoria, nuestro objetivo será sugerir esta definición así como apuntar algunas ideas sobre su operatividad. En primer lugar, la noción de performance puede atacarse de dos maneras fundamentales: la primera, objetiva, por comparación espacial; la segunda, subjetiva, por autocomparación. En la manera objetiva la organización $A$ se compararía a las organizaciones $B, C$, $D$, etc., que deben ser similares en sus objetivos. En la manera subjetiva la organización $A$ se compararía bien a ella misma mediante el conocido proceso Previsión-Realización-Desviación, bien mediante períodos o momentos diferentes [ $A$ (1974) con $A$ (1973), etc.], todo ello naturalmente en términos de los «Sistemas de valores» realizados. Desde el punto de vista de las técnicas a utilizar, Perrow (1968) señala cuatro formas de aprehender los sistemas de valores de las organizaciones: 1) mediante el análisis de los reglamentos interiores; 2) a través de encuestas realizadas cerca del personal de la organización; 3) por la observación del comportamiento de la organización, y 4) por inferencia de la contribución de la organización hacia el sistema social circundante. Aunque todas ellas pueden usarse simultáneamente, la primera va a ser descartada puesto que es sabido que la reglamentación formal no suele coincidir con la realidad informal.

El método a proponer se basará en una integración de los tres restantes y estará basado en una cierta teoría que puede llamarse descriptivo-normativa a partir de la noción de «sistema» y utilizando sus conceptos fundamentales, tanto objetivos (registro estadístico de hechos) como subjetivos (encuestas de opinión). Ya en un trabajo anterior (F. Parra Luna, 1975) se tuvo la oportunidad de tratar las nociones de performance política y performance nacional. Como Dahl, Laswell, Deutsch y otros habían señalado, una tal definición no es posible si primeramente no se parte de un modelo-patrón de valores suficientemente común y general para ser aceptado por el universo espacio-temporal sobre el que va a aplicarse. Este problema ha sido, creemos, aceptablemente solucionado en una primera fase del proceso hacia la comparación de las performances nacionales. Ello ha dado lugar al modelo compuesto por los diez grandes valores o ideales humanos detallados anteriormente, que corresponden a otras tantas grandes funciones político-sociales que toda organización social, cualquiera que sea su régimen o ideología, debe y de hecho se esfuerza en producir, poniendo más o menos énfasis en cada una de ellas. Descritos breve- 
mente en el mismo orden anterior, tenemos: 1. El valor Salud describe el nivel de bienestar personal físico y mental. 2. El de Seguridad, el ambiente social, cooperativo o conflictivo, moroso o integrado, de la organización. 3. La Riqueza Material, la productividad en términos pecuniarios. 4. El Conocimiento, los esfuerzos de la organización hacia la formación profesional, educación general e investigación científica. 5. La Libertad trata de las posibilidades ofrecidas a los individuos que componen la organización para modificar su funcionamiento. 6. La Justicia, la distribución equitativa de los medios destinados por la organización a sus miembros. 7. La Conservación de la Naturaleza, el no deterioro del patrimonio ecológico natural. 8. La Calidad de las Actividades, el desarrollo personal, cultural y humano del personal que compone la organización. 9. El Prestigio, la imagen externa de la organización. 10. El Poder, su fuerza (principalmente económica) frente a competidores.

El orden en que están enunciados estos diez valores no significa ni prioridad ni importancia relativa. Una vez estandarizados los datos empíricos que los representan hasta hacerlos comparables, darían lugar a la elaboración de un perfil axiológico propio de cada organización. En resumen, si la elaboración de estos perfiles es operacionalmente posible, ello supondría un progreso cierto desde los siguientes puntos de vista: 1. En cuanto a la definición y explicitación de los verdaderos objetivos de las organizaciones como medio de legitimización de su existencia (Etzioni, 1975) y como medio de conocimiento, comparación, control y mejora de los objetivos (Argyris, 1974), aparte de que en general supondrían la toma de conciencia del sistema de valores que subyace en cada organización. 2. En evitación del desplazamiento de objetivos (señalado primeramente por Michels y después por Merton y otros), si éstos no corresponden a la realidad social circundante. 3. Para conocer hasta qué punto el sistema de valores de una organización dada se acomoda a la evolución del sistema de valores de la sociedad en la que se halla inserta (la función de «adaptación» de Parsons) y, lógicamente, como medio de controlar las desviaciones entre los sistemas organizacional y social. 4. Para establecer comparaciones de performances totales y de estructuras de valores (perfiles) en el tiempo. Argyris (1974) acentúa la necesidad de estudios longitudinales o cronológicos, y Blau y Scott (1962) la necesidad de comparaciones espaciales o interorganizacionales. 5. A partir de un patrón general de valores se puede establecer una tipología de organizaciones enriquecedora de la teoría, ya que los sistemas de valores podrían representar todo el abanico posible de objetivos primordiales sin más diferencias que el grado de acentuación puesto en cada uno de ellos (Parra Luna, 1977), y donde sólo entonces resultaría correcto discernir entre MEDIOS y FINES de las organizaciones. 6. Como consecuencia de los puntos 2 y 3, para tener en cuenta posibles nuevas orientaciones en los procesos de decisión y racionalización progresiva (March y Simon, 1981), quienes consideran que no puede haber racionalización sin la adopción explícita de un modelo general de objetivos de la organización. 7. Las tres principales escuelas que se han ocupado del estudio de los objetivos de las organizaciones (económica, 
empresarial y sociológica) han intentado comprender el porqué de los cambios de objetivos en las organizaciones. Esto puede hacerse a través del estudio de las estructuras sociales organizacional y circundante, pero, desde luego, necesariamente complementadas con los propios sistemas de valores de las organizaciones, o, en otras palabras, explicar el cambio sólo es posible si se ponen en relación los sistemas de valores (interno y externo) y las fuerzas sociales estructurales que están al origen de su dinámica. 8. Finalmente, no es posible dejar de referirse a la supuesta crisis actual de valores, y si, como se dice, nuestra crisis es una crisis de civilización, parece obvio que la mera explicitación de los valores perseguidos por las organizaciones resultaría iluminativo. Incluso queda planteada la posible medida de comportamiento ético de las organizaciones (Van Gigh, 1978; Spaul, 1995; Minati, 1995). A partir de estas contribuciones teóricas se han efectuado esfuerzos para intentar operativizar el cuadro conceptual de valores presentado (p. ej., Parra Luna, 1975, 1977, 1983, 1993), principalmente en el campo de la empresa privada. El problema capital consistirá en cada caso en representar los Valores con un grado aceptable de validez científica y significación cuantitativa.

El proceso metodológico a seguir, según Lazarsfeld (1965), es conocido como «operacionalización» y requiere: $a$ ) la representación imaginada del concepto; b) la subdivisión en dimensiones teóricas; c) la selección de indicadores empíricos para representar cada dimensión; y d) la integración de los indicadores en un índice sintético. Disponibles los datos empíricos (objetivos y subjetivos) necesarios para lograr una definición válida (heurística) de las salidas $(Y)$ y de las entradas $(X)$, una organización social cualquiera, contemplada ahora desde la perspectiva transformadora de todo sistema social, producirá un concepto de Eficiencia Organizacional (T) que vendrá dada por la expresión $T=Y / X$, expresión comparable en el tiempo para la misma organización y en el espacio en relación a otras organizaciones comparables. Esta comparación es posible porque los niveles de " $Y$ » y de " $X$ » estarían estandarizados dentro de un intervalo común $(0$ = pésimo; 100 = óptimo $)$ que, además, es relativamente constante en el tiempo con el fin de presentar series cronológicas comparables. Ello se consigue si tanto el pésimo como el óptimo se hacen corresponder con cantidades (en los valores absolutos de cada indicador) lo suficientemente alejadas de lo previsible o real como para que no haya necesidad de modificarlas en períodos relativamente cortos; p. ej., no inferiores a diez años. Se trata, pues, de instalar para cada indicador empírico un intervalo duradero de variabilidad. Puesto que las salidas $(Y)$ representan un compuesto de los Valores del Patrón Referencial citado y éstos se han establecido en número de diez, la expresión " $Y$ » será igual a: $Y=\sum_{i=1}^{I D} y i / 10$, donde cada Valor «y» integrará a su vez lo objetivo o hechos « $y(o)$ » y lo subjetivo u opiniones " $y(s)$ » en la forma: $y=[y(o)+y(s)] /$ 2. Adelantemos entonces que la noción más directa y global de Eficiencia Sistémica viene expresada por el valor de " $T$ », que, como ya sabemos, depende de la relación entre las Salidas $(Y)$ producidas y las Entradas $(X)$ utilizadas. Más se produce de las primeras y menos se consume de las segundas, más alta la 
eficiencia del proceso transformador. La Teoría de Máquinas establece que la relación: $T=Y / X$, debe tender a valer la unidad, lo que termodinámicamente resulta imposible en sistemas cerrados. Si ello se consigue en ciertos sistemas es porque son inevitablemente abiertos y toman energía de sus entornos, resultando los sistemas más "consumidores" de energía cuanto mayor es su eficacia o alto el valor de " $T$ ". Precisamente los sistemas sociales se caracterizan porque intentan aumentar incesantemente el valor de $T$ a base, normalmente, de tomar grandes dosis de energía del entorno físico. El sistema social se caracteriza así por crear tanta negaentropía interna como entropia provoca en el entorno. Termodinámicamente hablando, el sistema social resulta ser el más depredador de todos. Pero en tanto que uno de los valores a realizar por los sistemas sociales modernos es el de Conservación de la Naturaleza, éstos deben procurar compatibilizar un alto nivel de salidas con el mínimo consumo de energía. Mientras el valor Conservación de la Naturaleza se realice a niveles aceptables (conservándola al máximo o consumiéndola al mínimo), el valor de " $T$ " (a igual nivel de «salidas») puede intentar elevarse sistemáticamente, ya que del mismo depende gran parte del progreso histórico de las sociedades. Teniendo en cuenta que " $T$ » expresa el grado de eficiencia de la Organización Social (en principio la variable explicativa global más relevante del sistema social), conviene seguir el principio metodológico adoptado que cuantifica tanto los niveles de entrada como los de salida entre el intervalo 0-100, llegando así a expresar el valor de " $T$ ", alrededor del valor 1 , pudiéndose establecer entonces: si $T=Y / X$ es mayor que 1 existe transformación positiva o multiplicativa; si es igual a 1 existe transformación neutra; y si es menor existe transformación negativa o reductiva.

El cálculo de las Entradas merece, sin embargo, una disección, ya que existen dos formas de calcular "X». La primera, que llamaré teórica o exhaustiva, tiene en cuenta, siguiendo el modelo general de sociedad (F. Parra Luna, 1983), los factores Estructurales (FE) disponibles, las Necesidades $(N)$ sentidas por la población y finalmente la Memoria $(M)$ del sistema, representada por el nivel de realizaciones $(Y)$ en épocas o períodos pretéritos. Incluso se puede tener en cuenta como Entrada el nivel de realizaciones o Sistema de Valores practicado por el Entorno $(\varepsilon)$ de esta forma: $X=f(F E, N, M, \varepsilon)$, que explicitaré mediante una relación integrada o sumativa en la forma: $X=F E+N+M+\varepsilon, \mathrm{y}$ en tanto que promedio $X=(F E+N+M+\varepsilon) / 4$. Mas resulta comprensible que, bien por carencia de datos, bien por dificultades diversas, no sea posible o conveniente el cálculo de "X» a base de integrar los niveles de $F E, N, M y \varepsilon$. Dada esta circunstancia, puede resultar conveniente sustituir dicha operación de integración por el importe total de los gastos (o costes totales) ocasionados por el sistema social en cuestión para un período determinado. Esta segunda forma de calcular « $X$ » resultará mucho más sencilla y seguramente práctica. Consistiría en tomar como Entradas el importe global del Presupuesto (anual, por ejemplo) o el de los gastos realizados para la «producción» de las Salidas $(Y)$. Este es el procedimiento que se aplicaría a la empresa, extensible a cualquier 
tipo de organización social o política que limite su acción a sus posibilidades presupuestarias. El cálculo de $X$ en estas condiciones se presenta sumamente fácil, ya que no existe organización que no disponga de presupuesto de gastos para cada período y conjunto de objetivos perseguidos. No obstante, un cálculo más refinado de la Eficiencia Organizacional (EO) exige algunas puntualizaciones. En primer lugar, la mejora o elevación de " $T$ " puede producirse cuando el descenso de " $X$ » supere al ascenso de « $Y$ », siendo posible que ambas desciendan en tal grado que la organización vaya desapareciendo paulatinamente con valores de " $T$ » progresivamente más altos. Luego, en la expresión de Eficiencia, ha de aparecer también el nivel de " $Y$ » en tanto que representa las salidas y exponente directo del grado de desarrollo del sistema. De igual forma, no pueden ser ignorados ni su posición relativa respecto al entorno más significativo (un sistema no resulta eficiente ni ineficiente, bueno ni malo, si no es en comparación con otros sistemas comparables), ni el equilibrio interno entre los niveles alcanzados por los diferentes Valores del Patrón Referencial (¿por qué determinados Valores - o indicadores concretos - se realizarían cercanos al óptimo, mientras que otros permanecerían alejados?). Completando por tanto la noción de Eficiencia Organizacional, es preciso señalar que el fin último de cualquier sistema u organización social es quintuple: a) Que el valor de " $Y$ " se incremente de período a período, lo que significa que el sistema se desarrolla en el tiempo ofreciendo a su población un sistema de valores más elevado. b) Conseguir el incremento de y productivamente, lo que quiere decir con unos niveles de Entradas (de gastos o costes) proporcionalmente menores, persiguiéndose que la expresión central $T=Y / X$ mejore no sólo por el incremento de " $Y$ ", sino también por el decremento de " $X$ ». La relación $Y / X$ debe, pues, tender a crecer. $c$ ) Que el vector $Y=\left\{y_{1}, y_{2}, \ldots, y_{10}\right\}$ gane en el tiempo homogeneidad entre los respectivos niveles de los Valores-Fines que representa; o, en otras palabras, que no presente unos Valores-Fines muy desarrollados próximos al 100 (óptimo) y otros pocos desarrollados próximos al $O$ (pésimo). La desviación típica de " $Y$ » debe, por tanto, tender a disminuir. $d$ ) Que el nivel global axiológico de desarrollo del sistema resulte igual o mayor que el de su entorno más significativo; la expresión final que describa entonces la Eficiencia Organizacional $(E O)$ resultaría así una función de: «T» (razón de transformación), de " $Y$ » (nivel de Salidas), de $\sigma_{y}$ (variabilidad interna de las salidas) y de la relación $Y / \varepsilon$ (comparación con el Entorno). Resumiendo, $E O=f\left(Y, T, \sigma_{y}(Y / \varepsilon)\right)$, que se puede explicitar como $E O=[Y . T .(Y / \varepsilon)] / 1+\sigma_{y}$, donde a la desviación típica se le suma la unidad de con el fin de evitar que su posible valor cero anule la expresión, o lo que es igual, $E O=Y^{3} / \varepsilon\left(1+\sigma_{y}\right)$, ya que $T=Y / X$. Fórmulas estas últimas que resultan más completas que la básica $T=Y / X$, deduciéndose de nuevo que no parece posible definir operacionalmente el concepto de Eficiencia de la Organización si no es mediante el recurso a la noción de sistema, puesto que es este concepto el que aporta los subconceptos de globalidad, entradas, salidas, transformación y retroalimentación, absolutamente imprescindibles para formular dicha definición en los términos de la relación entre los 
fines alcanzados $(Y)$ y los medios empleados $(X)$. Incluso tanto « $Y$ » como « $X$ » necesitan previamente ser contempladas a través del prisma sistémico globalista que supone la operación epistemológica de «sociologización», lo que quiere decir desde el punto de vista, intereses o necesidades que expresa la población del sistema o todos y cada uno de los componentes de una organización.

En realidad, la necesidad de conocer la Eficiencia (empresarial u organzacional) nace en un silogismo que parece irrebatible: 1 . La empresa está formada, sólo y exclusivamente, por personas con fines propios (los medios materiales y financieros utilizados carecen de ellos). 2. Dichas personas buscan únicamente satisfacer sus necesidades, lo que sólo pueden conseguir a través de los Valores. 3. Luego el segundo de los desafios formativos de todo DE consistiría en conocer (preferiblemente medir) la Eficiencia global de la empresa y la de cada uno de los subsistemas que la componen, en función, lógicamente, de los Valores producidos.

\section{EL CONCEPTO DE ENTORNO EMPRESARIAL}

Se asume que todo $D E$ debe conocer igualmente el entorno de su empresa, tanto para tomarlo como punto de referencia como para interaccionar de forma óptima con él mismo. Destacan entonces dos dimensiones: la epistemológica y la estratégica. La primera obliga a seleccionar cuál es el entorno más significativo de la empresa, debiendo tener presente que no existen reglas para determinar los entornos, sino que cada problema o circunstancia determinan el tipo o tipos de entornos, casi siempre con el carácter de contingentes. El $D E$ no queda ajeno, por tanto, al planteamiento epistemológico, desde cuya óptica precisamente ha sido avanzada ya una teoría de los entornos sucesivos que puede ayudarle. Así, el entorno más próximo de una empresa que presta el servicio $A$ puede serlo el conjunto de empresas que prestan el mismo servicio $A$ en un territorio cercano $(E)$; un segundo entorno puede estar formado por el sector nacional del producto $A\left(E_{2}\right)$, un tercero el sector europeo $A\left(E_{3}\right)$, y así sucesivamente. Desde esta perspectiva, tenemos la relación lógica de inclusión siguiente: $E_{1} \subset E_{2} \subset E_{3}$, y de donde se deduce que la cantidad de información (I) que se puede obtener de los entornos cumple: $I\left(E_{1}\right)<I\left(E_{2}\right)<I\left(E_{3}\right)$, mientras que el coste $(C)$ de dicha información, al resultar los entornos progresivamente mayores, cumplirá que: $C\left(E_{1}\right)<C\left(E_{2}\right)<C\left(E_{3}\right)$, lo que obliga, desde una perspectiva comparativa o evolutiva (inevitablemente epistemológica), a maximizar la relación: $I\left(E_{1}\right) / C\left(E_{1}\right)$ en comparación a las de $I\left(E_{2}\right) /$ $C\left(E_{2}\right)$ y $I\left(E_{3}\right) / C\left(E_{3}\right)$, única manera de optimizar resultados cuando se trata de utilizar entornos.

El tratamiento del Entorno desde la dimensión estratégica, sin embargo, puede resultar más complejo ya que será preciso subdividir éste en una serie subentornos. Si seguimos el modelo/cubo propuesto por Paul (1990), compuesto por: cinco "focos estratégicos» (diagnóstico de los problemas del sector; identificación de los beneficiarios; demanda del programa de servicios; oferta 
del programa de servicios; e identificación de los actores y grupos), cuatro «segmentos» (político, económico, sociocultural y tecnológico), y tres "dimensiones» (tamaño, incertidumbre y diversidad), se percibe entonces la complejidad de un tal análisis del Entorno ya que exigiría una disección de los 5×4×3=60 subdimensiones resultantes. Como iniciación a este análisis, se puede emplear el método de subdividir el entorno en lo que Paul llama «segmentos»: p. ej., Económico ( $E$, o evaluación del poder de compra de la sociedad y cuyos primeros indicadores pueden ser los cambios en el PIB, el IPC, el paro, comercio exterior, etc.; Social (S), o análisis de los cambios demográficos en la población; Tecnológico (T), o apreciación de los cambios científicos o técnicos susceptibles de modificar los hábitos de vida; Cultural (C), o apreciación de los hábitos socioculturales de vida y, específicamente, medición del grado de aceptación del producto $A$, o de sus derivados; el Político ( $P$ ), o registro de las contingencias fiscales, laborales, mercantiles y otras que pueden afectar a la empresa, $y$, finalmente, lo que puede llamarse Competitivo $(\mathrm{Cm})$, o análisis del poder económico, mercado, grado de agresividad, creatividad, etc., de las empresas del mismo sector de competencia. La relación entre estos subentornos es entonces de intersección común donde se maximiza un nuevo subconjunto $(A)$ en la expresión $A \cap(E, S, T, C, P, C m)$, lo que apunta a que de cada subconjunto tome la parte compatible con la del resto de los subconjuntos y con los medios limitados (principalmente financieros) disponibles. Operacionalizar estos conjuntos con indicadores empíricos, ni es difícil, dado el nivel de información estadístico existente, ni resulta prescindible si las empresas persiguen su buen gobierno, cada una al nivel que corresponda a su dimensión y capacidad económica. Lo difícil es lograr maximizar el área común $A$ que optimizaría la interacción empresa-entorno. Una manera intuitiva y aproximada de llevar a cabo esta operación consiste en contemplar los cambios conjuntados que ofrece el Entorno, como muestra el cuadro 1, para tratar de adaptar la empresa a dichos cambios y a las nuevas necesidades y posibilidades que sugieren. Por difícil que resulte la operación de maximizar el área $A$, la empresa no puede dejar de contemplar periódicamente las transformaciones de toda índole producidas y la reacción tanto de la competencia como del resto de las instituciones ante las mismas. Está en juego, lógicamente, su futuro.

Cambios culturales cuyo análisis pormenorizado, combinado con el análisis de los medios organizativos, financieros y otros, debería dotar a la empresa de una determinada capacidad de reacción que le permitiera su continua readaptación al Entorno, lo que algunos autores - Archier y Serieuyx (1985) llaman «Reáctica empresarial». De donde se deduce el tercero de los desafíos formativos: ningún empresario debería desconocer coómo calibrar los cambios recientes acaecidos en sus entornos más significativos y las expectativas posibles que generen. 


\section{CUADRO 1}

Un análisis del entorno empresarial

Tendencias culturales

1. Incremento de la esperanza de vida. Envejecimiento/descenso de población.

2. Preocupación por la ecología y medio ambiente.

3. Tendencia hacia el pacifismo Antimilitarismo. Insumisión.

4. Neoliberalismo socioeconómico.

5. Desarrollo de la tecnología, la ciencia y la educación.

6. Incremento del tiempo libre. Desempleo.

7. Mayor sensibilidad hacia la equidad. Eficacia informática de los controles fiscales.

8. Menor necesidad de igualdad.
Efectos posibles sobre las empresas

Necesidad de producir una cantidad y variedad de servicios para la tercera edad mayor, desde servicios sociales a domicilio hasta producción industrial de aparatos e instrumentos para minusválidos, pasando por la producción y consumo de productos dietéticos. Crisis del tabaquismo. Consumo de fármacos. Mejora de la enseñanza por cambio en la relación profesor/número de alumnos.

Control de desechos. Investigación sobre sus efectos. Producción de tecnología medioambiental. Gama de carencias y posibilidades enorme, desde nuevos sistemas de vertido y depuración hasta las técnicas de reordenación del territorio, pasando por la producción de productos biodegradables. Repoblación forestal. Arborestación y ajardinamientos. Instalación de viveros. Producción de energía solar y eólica. Desviación de industrias contaminantes hacia países menos industrializados.

Transformaciones de la industria armamentista en utilitaria. Proyectos internacionales de colaboración técnica y educativa.

Crisis sindical. Potenciación del sindicalismo. Tendencia a la negociación individual de salarios. Paro no subsidiado. Eventualismo. Precariedad en el empleo. social. Crisis del Estado y mayor peso de la sociedad civil. Crisis de la seguridad social, laboral y ciudadana. Aparición de actividades privadas para estos fines.

Necesidad de participar en programas de investigación y estudios de carácter internacional. Nuevas necesidades de formación. Colaboración universidad-empresa. Nuevas tecnologías de formación a distancia. Reducción de la jornada laboral. Jubilaciones y bajas anticipadas. Crisis del sentimiento religioso. Aprendizaje de idiomas.

Necesidad de producir bienes y servicios para el ocio en cantidad y variedad crecientes (turismo, viajes, deportes, libros, vídeos, etc.). Desarrollo de sistemas de pensiones empresariales.

Necesidad de transparencia contable y honestidad fiscal. Implantación de incentivos de participación. Flexibilidad de salarios en función de la productividad. Disminución del fraude fiscal.

Mayor amplitud del abanico de remuneraciones. Sistemas de retribuciones individuales. Deshomogeneización creciente de salarios. Crisis de la negociación colectiva. 


\section{CUADRO 1 (continuación)}

\section{Un análisis del entorno empresarial}

Tendencias culturales

9. Potenciación de la imagen externa y la presentación.

10. Potenciación de las relaciones públicas.

11. Revalorización del hedonismo y materialismo.

12. Integración económica supranacional.

13. Tendencia hacia la empresa integrada.

14. Terciarización de la economía. Peso creciente de la nueva sociedad posindustrial o de información.

15. Creciente incorporación de la mujer al trabajo.

16. Desarrollo de la competitividad y las leyes del mercado.

17. Incremento de la población periférica.
Efectos posibles sobre las empresas

Necesidad de producir bienes y servicios para la presentación de la oferta. Cumplimiento de la legalidad en general. Necesidad del cuidado de marca y del prestigio de empresa. Consumo de publicidad, moda y marcas. Preocupación por la gestión ética.

Influencia de la comunicación externa. Valoración de las relaciones sociales. Producción y venta de mailings y bancos de datos.

Producción de bienes y servicios de creciente nivel de comodidad y satisfacción material. Desarrollo de la tecnología automatizada y cibernética. Instalación de edificios y hogares inteligentes. Reducción del trabajo penoso. Robótica. Cultivo del cuerpo físico. Paralelamente, consumo de drogas.

Necesidad de incrementar la competitividad por la futura libre circulación de capitales, mercancías, servicios y personas. Crisis del nacionalismo económico. Incremento del comercio exterior. Internacionalización de los mercados y de los recursos financieros. Fusión de empresas. Necesidad de alianzas o joint ventures internacionales. Desarrollo de las redes o grupos de empresas.

Cambios en la organización empresarial hacia la integración y participación del personal. Concepción de la empresa como sistema "suma no cero». Superación paulatina del antagonismo empresario/trabajador. Cambios en la cultura empresarial. Explicitación y replanteamiento del sistema de valores perseguidos.

Diseño y producción de sistemas de información y comunicación como nueva energía de la sociedad posindustrial.

Incremento de la gama de electrodomésticos. Construcción de hogares inteligentes. Nuevos servicios de atención a la infancia.

Orientación hacia el cliente y preocupación por la calidad total.

Movimientos migratorios. Inseguridad ciudadana y laboral. Racismo y xenofobia laboral. Eventualismo. 


\section{LA EMPRESA COMO SISTEMA «SUMA NO CERO»}

En contraste con los enfoques sociológicos clásicos que enfatizan como elementos teóricos esenciales de la sociedad o los sistemas sociales las formas (Simmel), acciones (Parsons), roles (Mead), interacciones (Schutz), intercambios (Blau) o comunicaciones (Luhmann), entre otros, conviene resituar la organización social en tanto que esencialmente compuesta por personas concretas (Miller, Deutsch, Bailey) que sienten, intuyen, racionalizan o persiguen ciertos valores que satisfagan sus necesidades. La empresa, como cualquier otro sistema social, hay que plantearla en tanto que formada por personas físicas con todos sus defectos y virtudes, pero, sobre todo, especialmente dotadas para la crítica, la invención, la creatividad y la previsión de su futuro. En ello estriba la diferencia esencial entre los sistemas sociales humanos y el resto de los sistemas: en la capacidad, muchas veces escondida, adormecida o latente, para criticar, recrear y reinventar su propia organización social. A pesar de ello, las organizaciones humanas son escasas veces tratadas en la práctica como sistemas "suma no cero», que es precisamente lo que son. Desatención epistemológica que lleva a procesos de negociación (p. ej., convenios colectivos donde trabajadores y empresarios discuten sobre salarios, condiciones de trabajo, productividad, etc.,) con resultados no tan positivos para la empresa y la sociedad como cabría esperar. La abundante literatura sobre Negociación, desde las pioneras obras de Nash $(1950,1953)$ y Donnatt y Johnson (1951) hasta los trabajos mas recientes de Touzard (1981), Pruit (1981), Wall (1985), Elster (1991), Kennedy et al. (1991) o Lax y Sobernius (1991), ha analizado una gran variedad de procesos y casos que van desde la negociación política de carácter internacional hasta las negociaciones entre parejas ante casos de divorcio, pasando por las que llevan a cabo las personas o sociedades simultáneamente como en el caso de las coaliciones empresariales y, cómo no, en las típicas negociaciones de convenios colectivos de empresa.

En este punto voy a presentar resumidamente un esquema de negociación poco tratado en la literatura y a su vez concreto y de general aplicación, ya que se trata de la típica negociación Empresa-Trabajadores hacia un nuevo convenio de relaciones económicas y laborales; y porque no parece existir empresa medianamente importante sin algún tipo de acuerdo sobre estas materias. La diferencia del enfoque va a consistir, primero, en criticar a la organización empresarial que considera que su producto es constante o "suma cero" (lo que evidentemente no es así) y, segundo, en que la negociación se va a contemplar como un proceso complementario en el desarrollo de la organización. Negociar en este sentido no sería tanto redistribuir la masa de beneficios empresariales de una manera óptima para ambas partes negociadoras, sino, sobre todo, iniciar una vía que conllevaría la integración de dos operaciones: a) el aumento de las expectativas de «beneficios» (por supuesto no sólo económicos) de la empresa, y b) el aumento de las expectativas de una mejor, o en todo caso más participada, redistribución de los mismos. Es conocido que la actitud de parti- 
da básica en la empresa que se dispone a negociar un convenio colectivo con sus trabajadores es la siguiente: la empresa es lo que es y no da mas de sí. En el fondo se parte de la última situación histórica cuyo resultado final se hace igual a una constante; p. ej., 100. De forma que si el empresario $(A)$ obtiene 60 , a los trabajadores $(B)$ sólo les queda 40, y si éstos se llevaran 70, al empresario le quedarían 30. Aplican el concepto teórico de organización «suma cero» donde dos más dos son inevitablemente cuatro, sin terminar de percibir adecuadamente que están tratando con un tipo de organización (la empresa) que, como todas las organizaciones humanas, no depende (o sólo en parte) de lo que ha hecho, sino de lo que podría hacer. Potencialmente hablando, sin embargo, en ninguna organización humana $2+2$ suman forzosamente 4 , sino que puede resultar 5, 20, 40 ó - $37 \ldots$, todo depende de la combinación funcional que se acierte a proporcionar a sus elementos, no existiendo en principio límites ni techos en la contemplación (teórica) de su futuro. De ahí el enorme desarrollo constatado en algunas empresas, frente al resultado negativo de otras como cuando la empresa quiebra o el matrimonio se divorcia. Una futura regla de oro en la moderna gestión empresarial basada en sus recursos humanos podría enunciarse así: la empresa será, muy probablemente, lo que proyecten sus personas componentes, y el resultado de este deseo dependerá de la reorganización de elementos (personales, físicos, monetarios...) que acierten a configurar como organización dichas personas. Principio que puede ser utilizado en un momento previo a la negociación para, replanteándose teóricamente el carácter "autopoiético» (Maturana y Varela) de la empresa, obtener los mejores resultados posibles. Por ponerlo en términos gráficos, las negociaciones actuales típicas se fundamentan en la organización «suma cero» (gráfico 1), donde la línea $\mathrm{c}$-d representa la utilidad disponible a repartir entre el empresario (A) y los trabajadores (B).

Si A toma el nivel de utilidad «e», a B sólo le corresponderá el nivel «f»; y si A tomara el nivel «g», entonces a B le correspondería el nivel «h». En la negociación competitiva en sistemas «suma cero» se trata entonces de maximizar la utilidad para ambos contendientes aproximándose lo más posible a los niveles «i» para el negociador A y «j» para el B, lo que equivale a maximizar el área geométrica bajo la línea c-d. Pero esta línea c-d impone unos límites (históricos y otros) impropios de toda organización social. Porque no se trata de maximizar el área $(\mathrm{O}, \mathrm{i}, \mathrm{p}, \mathrm{j})$, ni siquiera de superarla pasando a la línea c'-d', sino de resituarse en otro concepto de empresa que toma un forma flexible (multiplicativa o negantrópica las más de las veces, reductiva o entrópica las menos) en función de las expectativas de credibilidad empresarial (creación de sinergias) hasta convertirla en una organización «suma no cero». La situación creada queda entonces reflejada en el gráfico 2, donde la línea o-d puede recorrer ahora los puntos «e», «f», «g» capaces de suministrar crecientes utilidades a «A» $\mathrm{y} « \mathrm{~B} »$.

Dicho recorrido e, $f, g, \ldots$ es posible gracias a que, desde esta óptica, se abre un proceso dialéctico de crítica, contracrítica y síntesis en la adopción de 


\section{GRAFICO 1}

Negociación en sistemas "suma cero"

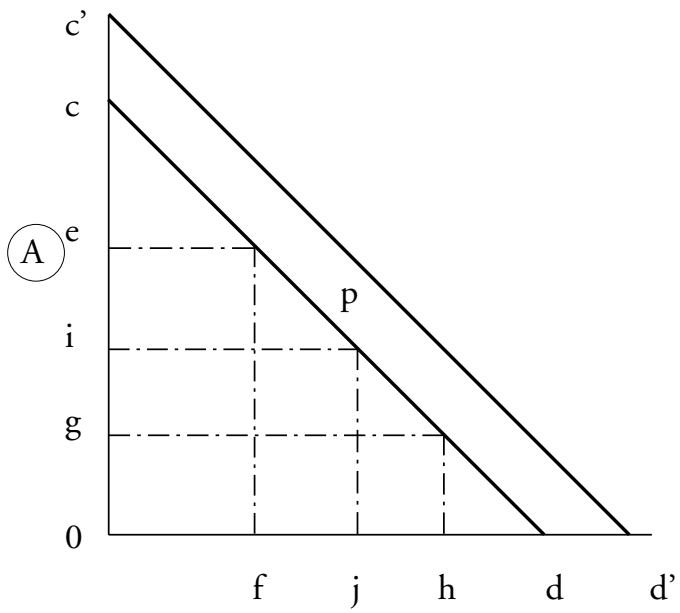

\section{B}

\section{GRAFICO 2}

Negociación en sistemas «suma no cero»

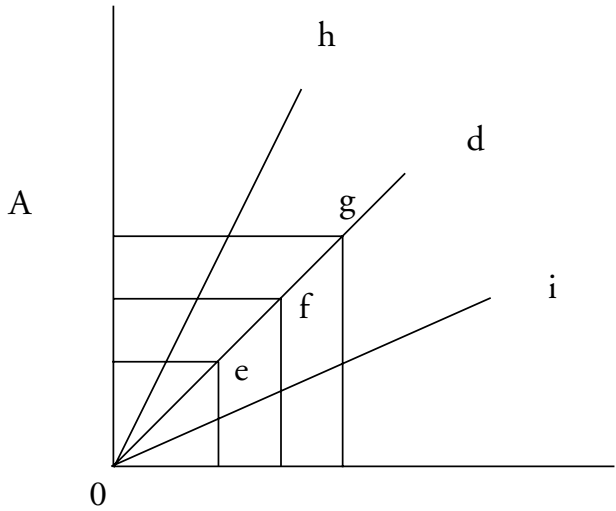


medidas susceptibles de introducir sinergias en cualquier empresa. No sin antes decir que las líneas $o-h$ y $o-i$ corresponden a distintas opciones en la distribución de las utilidades generadas. La primera, cuando al empresario o representante del capital corresponde una mayor proporción de las utilidades (p. ej., caso de la empresa de nueva creación), la segunda cuando es a los trabajadores a quienes corresponde dicha mayor proporción (caso de la empresa histórica) (Montero de Burgos, 1990).

\section{El proceso de introducción de sinergias}

Por sinergia se entiende la capacidad que tiene una decisión organizativa, una medida de gestión o una determinada combinación de elementos del sistema, para mejorar la utilidad total o axiológica del mismo. Un caso claro de acciones de este tipo podría producirse con motivo de las negociaciones colectivas. Supóngase que los trabajadores solicitan un incremento salarial demasiado elevado para las expectativas empresariales. La respuesta del empresario no debería ser la de intentar rebajar el incremento pedido (lo que se suele hacer sistemáticamente), sino hacerlo depender, p. ej., del aumento de la productividad global de la empresa. Enfrentados los trabajadores a esta situación argumentarían que resulta imposible hacerse cargo de la productividad si no participan en la gestión de la empresa, solicitando por ello tal posibilidad. A su vez, el empresario exigiría, incluso de una manera formalizada, la prevalencia de los intereses empresariales por encima de posibles intereses a corto plazo de los trabajadores, debiendo asumir todos que lo primero es la seguridad y el futuro de la empresa como ente generador de utilidades. Pero para llevar a cabo una verdadera participación de los trabajadores, éstos exigirían la lógica transparencia contable interna, lo que obligaría al empresario a exigir a su vez el debido compromiso sobre el secreto de los datos empresariales. Todo ello requeriría que el empresario comenzara a confiar en sus trabajadores como «socios» en lugar de considerarlos «enemigos» encubiertos dispuestos por sistema a trabajar lo menos y cobrar lo más. Cambio de actitud del empresario que exigiría a su vez de los trabajadores la práctica de un sindicalismo de empresa centrado en conseguir la mejor gestión posible, lo que a su vez implicaría tanto la participación en los beneficios reales de la empresa (última exigencia de los trabajadores) como en la asunción por éstos de las pérdidas si las hubiera (última exigencia del empresario). La negociación se convertiría así en un zigzagueante proceso con base en un eje central igual a cero y unos máximos (p. ej., de 100) a izquierda y derecha del actual, empobrecedor y homeostático eje central. Puesto que todas y cada una de las reivindicaciones representan en principio sinergias (introducen eficacia en el sistema), lo serán tanto más cuanto más se alejen del nivel cero y se acerquen a 100. El proceso de negociación social en "suma no cero» resulta, pues, sinérgico y negaentrópico por naturaleza. Si a la primera reivindicación de incremento salarial se responde con otra reivindicación sinérgica como es la 
exigencia de un paralelo aumento de la productividad, se dará pie a que se encadenen el resto de las reivindicaciones, lo que con seguridad no sucede actualmente en los innumerables casos de negociación. En efecto, cuando se celebran las típicas negociaciones entre empresarios y trabajadores en torno, p. ej., a reivindicaciones salariales, las partes se sientan a la mesa con una firme actitud generalizada: unos "dar el mínimo, otros obtener el máximo». Craso error de concepción ontológica y epistemológica de lo que es un sistema social, a partir de cuyo error se continúa regateando al más puro estilo de mercadillo árabe hasta alcanzar aceptables pero mediocrizantes posiciones intermedias (si $A$ pide el 8 por 100 y $B$ ofrece el 5 por 100 , lo mejor es aceptar el 6,5 por 100), y ello en bandas salariales, horas extras, contratos temporales, despidos, etc. Posiciones éstas intermedias - yo cedo, tú cedes- que restan potencia al sistema en lugar de añadirla, decisiones impropias de un sistema inteligente que debe formular reivindicaciones sinérgicas para así reordenar e introducir movilidad combinatoria en los elementos, las partes y los subsistemas a fin de conseguir la máxima eficiencia. Tales acuerdos basados en la media aritmética de las posiciones no son ninguna barbaridad no obstante, ya que permiten a la empresa ir tirando sin mayores conflictos, aunque, eso sí, hundidos en la mediocridad sinérgica que generan las decisiones que sustraen potencialidad en lugar de añadirla. ¿No resultaría más productivo conceder el 8 por 100 , e incluso más aún, pero a cambio de hacerlo depender de la productividad o los beneficios? ¿No sería, pues, más potenciador para la empresa organizar sus elementos (por ejemplo, coordinando los intereses empresariales y sindicales) en lugar de autoestorbarse —cuando no autodestruirse- en dos bloques enfrentados? Cuando el empresario sabe que sus empleados van a mantener secreto absoluto sobre procesos o datos internos no existirá inconveniente en facilitarles la información pedida, sobre todo si va acompañada de otros cambios de actitud de los trabajadores, terminando por implantarse una política informativa clara y honesta si se considera beneficiosa para la empresa. A su vez, la implantación de un sistema informativo transparente favorece la práctica y el desarrollo de una acción sindical centrada en la empresa, mucho más celosa del compromiso adquirido con la empresa y de sus resultados económicos que comprometida con el sindicalismo nacional o de clase (se sabe, por ejemplo, que los trabajadores suecos que se sientan en los Consejos de Administración y los Comités Ejecutivos de las empresas defienden muchas veces posiciones pro-patronales frente a sus compañeros porque son conocedores de las dificultades a las que se enfrenta la empresa). Si los trabajadores actúan entonces movidos por los principios de un estricto sindicalismo de empresa, la confianza de los empresarios puede llegar a ser total, lo que a su vez retroalimenta positivamente la prevalencia de los intereses empresariales sobre los individuales. Es el típico caso de retroalimentación social positivo, donde las sucesivas acciones $A_{l}$, $A_{2}, \ldots A_{n}$ del actor $A$ han provocado sucesivas respuestas $B_{1}, B_{2} \ldots B_{n}$ del actor $B$, haciendo que la utilidad (axiológica) total tanto del actor $A(Y(A))$ como 
del actor $B(Y(B))$ aumenten paulatinamente con el tiempo, cumpliéndose la sucesión: $Y(A)_{1}<Y(A)_{2} \ldots<Y(A)_{n}$ e igualmente $Y(B)_{1}<Y(B)_{2} \ldots<Y(B)_{n}$, lo que no es más que el resultado de la estrategia de la cooperación frente a la de confrontación dinámicamente contemplada. La empresa se convertiría así en un sistema de interdependencias de reivindicaciones $(R)$ mutuas que se puede formalizar como sigue: $R_{1}=f\left(R_{2}, R_{3}, \ldots R_{n}\right) ; R_{2}=f\left(R_{1}, R_{3}, \ldots R_{n}\right) ; R_{n}=\left(R_{l}, R_{2}, \ldots\right.$ $R_{n-1}$ ), residiendo en este último sistema de funciones el "quid" de la cuestión que resume el proceso. Cualquier sinergia $(R)$ introducida por cualquiera de las partes, en no importa qué tipo de reivindicación ni el orden en que se produzca, termina generando, con arreglo a los principios de retroalimentación positiva, el desarrollo integral del sistema hacia límites desconocidos. El zigzagueante proceso de reivindicaciones se convierte, pues, en una eclosión del conjunto de reivindicaciones donde ahora todas las peticiones que entraron en juego, al retroalimentarse positivamente, hacen posible el progreso. ¿Es esto nuevo? En el fondo es tan viejo como la viñeta de los dos burros en desacuerdo ante sendos montones de heno. Pero, por absurda que nos parezca tal actitud, seguimos ciegamente empeñados, couteau entre les dents, en alcanzar una posición intermedia, falsamente equilibrante, pero empobrecedora y entumecedora del potencial y del desarrollo de la empresa.

Quizás merece entonces la pena diseñar o sugerir algunas reglas de cumplimiento obligado cuando de negociaciones en sistemas «suma no cero» se trata, a saber: a) Considerar que casi todas las peticiones o reivindicaciones de las partes interesadas introducen un determinado grado de sinergia positiva (raramente negativa) en los sistemas empresariales, ya que cuando algo se reivindica con fuerza por un colectivo, sea éste sindical o empresarial, es porque muy probablemente existen fuertes razones que lo justifican. b) Conocer y cuantificar con la mayor precisión posible los grados de sinergia $(S)$, situándolo entre $O$ y 100 de cada una de las reivindicaciones. c) Calibrar entre 0 y 100 los grados de intensidad $\left(I_{s}\right)$ con el que se expresa cada reivindicación, asumiéndose que su no satisfacción implicaría un grado paralelo de frustración. d) Conocer el Esfuerzo $(E)$ a realizar, también entre 0 y 100 , para cada una de las reivindicaciones, así como su correspondiente peso relativo $I_{E}$. La máxima sinergia global o Potencial de Desarrollo Empresarial (PD) se conseguiría satisfaciendo las reivindicaciones en función directa del grado de Sinergia $(S)$ que introduzcan y de la Intensidad (I) con que son solicitadas, e inversa del Esfuerzo (E) que implica su adopción y de su correspondiente "peso». Se trata entonces de maximizar la expresión: $P D=S I_{s} / \Sigma\left[\left(E_{e}+E_{t}\right) / 2\right] I_{E}$, donde los cinco términos intervinientes son promedios aritméticos (entre 0 y 100) obtenidos por encuesta y donde $E_{e}$ y $E_{t}$ significan grados de esfuerzo a realizar (siempre en términos de porcentaje) por empresarios (e) y trabajadores $(t)$. Si $P D>1$ significa que la empresa posee un potencial de desarrollo que está sin aprovechar, justamente en la medida que PD supere a la unidad. Por ejemplo, un $P D=1,4$ significa que la empresa tiene la posibilidad de incrementar su eficacia en un 40 por 100 más que el esfuerzo a realizar para obtenerlo. Por el contrario, si 
$P D<1$ significa que el esfuerzo a realizar es tan grande que no compensaría la sinergia obtenida. Un $P D=0,5$ indicaría que el "Beneficio" obtenido sólo alcanzaría la mitad del esfuerzo (o coste) realizado. En el primer caso hay un sobrante de energía no movilizado; en el segundo, lo que falta es energía y lo que se impone es un cambio de actitudes para crearlas y encaminarlas hacia la obtención de sinergias. Todo ello desde el punto de vista de las expectativas subjetivas de los actores empresariales, que, a fin de cuentas, son los que marcan el futuro empresarial con sus acciones. Mas estas evaluaciones, fáciles de determinar por otra parte, apenas se llevan a cabo en las empresas de manera sistemática y formalizada. En resumen, la negociación como proceso sinérgico exige que se produzca en una organización asumida subjetivamente por los negociadores como "suma no cero". Desde dicha óptica, los negociadores podrían aplicar la siguiente normativa: 1) Prever el mayor número de reivindicaciones posible por ambas partes negociadoras. 2) Seleccionar sólo aquellas reivindicaciones susceptibles de introducir sinergia en el sistema. 3) Solicitar el máximo nivel posible (entre 0 y 100) para cada reivindicación o pareja de reivindicaciones contrapuestas. 4) Igualar el número de reivindicaciones de una y otra parte. 5) Ordenar su presentación de modo que faciliten el descrito proceso de desarrollo sinérgico en zig-zag. En estas condiciones, el giro epistemológico dado hacia los sistemas "suma no cero" supondría una nueva perspectiva en el desarrollo de las organizaciones. De donde se deduciría el cuarto de los desafíos formativos: ningún empresario debería desconocer que su empresa es un sistema "suma no cero" $y$, por tanto, con posibilidades naturales autopoiéticas o automultiplicativas.

\section{UN PLAN ESTRATEGICO-PARTICIPATIVO DE FORMACION}

Contemplada la empresa a vista de pájaro en el laboratorio teórico, destacan sus dos grandes ejes: el teleológico (la búsqueda de fines) y el instrumental (la utilización de medios). Si en el primero se aprecian claramente las dimensiones teóricas de Entradas, Transformación, Salidas, etc., en el segundo destacan cuatro dimensiones: Estrategia, Formación, Dirección y Recursos Humanos. Cuatro variables organizacionales éstas que, aparte de representar la base explicativa de las teleológicas, forman el meollo y origen de la acción empresarial práctica. Las denominaremos Plan Estratégico (PE), Plan de Formación (PF), Directivo Empresarial (DE) y Recursos Humanos $(R H)$. Los desarrollos teóricos apuntados requieren, lógicamente, una revisión y replanteamiento, no sólo de la formación académica y conceptual básica de los $D E$, sino de los mismos planes de formación empresariales, los cuales habrían de perseguir la formación de su personal de una manera más participativa e integradora, capaz de hacer frente a los problemas estratégicos que se le presentan a la empresa. De la misma forma que la consideración de la empresa como "sistema suma no cero» implica la participación integradora de todos sus elementos y ámbitos persona- 
les en su gestión, no podría existir un adecuado plan de formación empresarial sin la participación de todos sus componentes, cada uno al nivel que le corresponda por su función o formación. Incluso se verá reforzada y estimulada la propia formación del $D E$ a través de la interacción-participación en el proceso formativo general. Lo que he llamado "Plan Estratégico Participativo de Formación" es producto de la interacción de las cuatro variables instrumentales señaladas.

Como muestran las flechas del gráfico 3, no podría existir una adecuada formación del $D E$ sin la asunción de un plan estratégico previo, y éste no podría implementarse sin un plan de formación general donde intervengan no sólo el $D E$, sino, prácticamente, la totalidad de la plantilla de la empresa. En consecuencia, el modelo dinámico se expande en cuatro momentos: 1) la iniciativa la toma $D E ; 2)$ logrando la participación del personal; 3) estableciendo el Plan Estratégico; y 4) implementando el Plan de Formación. Las variables $D E$ y $R H$ son movilizadoras; las $P E$ y $P F$ resultantes. El eje movilizador pasa por la participación del personal; el eje resultante por la imprescindible reproyección de la empresa frente a las dificultades del Entorno. De ahí que responder a la pregunta básica de "¿cuáles son las necesidades de formación de la empresa?» implique forzosamente el planteamiento y definición de la variable $P E$ y su puente causal hasta idéntico planteamiento y definición de la variable $P F$. El modelo que se emplea para la primera exigiría en cualquier caso realizar la siguiente radiografía empresarial: a) resultados económicos; b) penetración en el mercado; $c$ ) situación frente a la competencia; $d$ ) plan estratégico a medio y largo plazo; e) planes de márketing anuales; $f$ ) consecución de objetivos sectoriales y departamentales; $g$ ) grado de satisfacción de los clientes; $h$ ) garantías cursadas; i) calificación del personal; $j$ ) imagen de la empresa; $k$ ) cultura de

\section{GRAFICO 3}

\section{Interrelación de variables instrumentales}

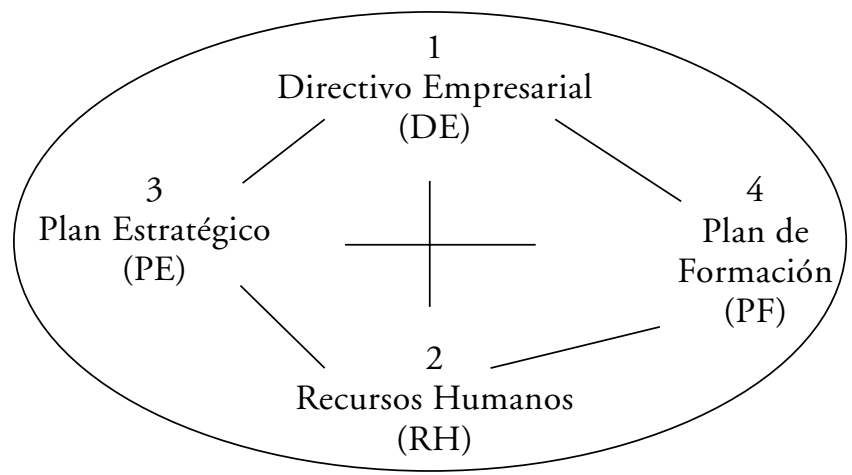


empresa; l) nuevas tecnologías y métodos de trabajo; y $m$ ) evolución del mercado. Una vez definida la estrategia básica de la empresa, el modelo que se emplee para la segunda debe comprender al menos las dimensiones «Sujeto de la formación", "Nivel de la Formación», "Areas de conocimiento", "Grado de urgencia», "Actor de la Formación» y "Control y Evaluación de la Formación», o más analíticamente responder a las siguientes preguntas: 1. ¿A quiénes debe formarse?: a) Dirección general/alta dirección; b) Equipo directivo; c) Mandos intermedios; d) Personal de base. 2. ¿A qué nivel?: a) Estrategia empresarial (posición y perspectivas en relación a la competencia); b) Cambio cultural (fundamentalmente cambio de actitudes éticas, sobre participación e integración del personal, etc.); c) Recualificación ocupacional (adiestramiento en nuevas especialidades); d) Mantenimiento de conocimientos y competencias. 3. ¿Sobre qué áreas básicas?: a) Márketing; b) Producción; c) Organización y logística; d) Comercial; e) Recursos humanos; $f$ ) Finanzas; $g$ ) Técnicas específicas de la empresa. 4. ¿Con qué grado de urgencia?: a) Muy urgente; b) Bastante urgente; c) Urgente; d) Menos urgente. 5. ¿Quién debe responder a las preguntas anteriores?: a) El máximo responsable de la empresa; b) Su cuerpo directivo; c) Consultores externos; d) Mandos intermedios; e) Representantes sindicales; y f) El propio personal afectado. 6. Y, finalmente: ¿Cómo evaluar la formación? a) Métodos de evaluación interna: $a_{1}$ ) revisión de grupo, $a_{2}$ ) cuestionario individual, $a_{3}$ ) apreciación global, $a_{4}$ ) resultados prácticos, $a_{5}$ ) entrevista, y $a_{6}$ ) evaluación retrasada; o $b$ ) Métodos de evaluación externa: $b_{1}$ ) tests de conocimiento, $b_{2}$ ) tests de técnicas, $b_{3}$ ) aplicaciones prácticas, $b_{4}$ ) análisis de conductas, y $b_{5}$ ) cuestionarios de semántica diferencial (Rae, 1986). Amplio arco de consideraciones y posibilidades cuya decisión puede resultar extremadamente compleja. De ahí que resulte conveniente que, al menos directivos y personal (a través de sus representantes), se enfrenten por separado a la necesidad de responder inicialmente a estas preguntas.

En principio, pues, recordemos que la empresa necesitaría: 1. Técnicas para percibir y analizar las tendencias del sistema de valores (económico, tecnológico, social, etc.) del entorno. 2. Técnicas para evaluar su potencial de respuesta, sus fuerzas y sus debilidades, incluyendo el nivel de formación de plantilla actual. 3. Técnicas para elaborar una estrategia viable como reacción adaptativa, incluyendo un diseño de la plantilla ideal. 4. Técnicas para diseñar e implementar un plan de formación que responda al punto anterior. 5. Técnicas para vigilar y controlar los resultados y el replanteamiento continuo de los objetivos. Y si este savoir-faire instrumental va a necesitar una formación en los altos niveles de la empresa, tampoco es difícil constatar que el proceso formativo deberá expandirse hasta el más bajo de los niveles y, además, con una sensibilidad especial para controlar los resultados. De donde se deduce que un plan de formación ha de reunir al menos seis requisitos básicos: 1 . Ha de ser estratégico o derivarse de la respuesta empresarial frente al entorno. 2. Ha de ser global o debe implicar a todas las funciones de la empresa. 3. Ha de ser participativo o debe ser definido, al menos, por todos los que vayan a participar en él. 
4. Ha de ser obligatorio o debe concebirse como una función o trabajo más. 5. Ha de ser dinámico o debe adaptarse a las circunstancias cambiantes del entorno y de la empresa. 6. Ha de ser rentable o su eficacia y rentabilidad deben ser evaluadas y controladas. Cuantos más diversos sean sus orígenes y más numerosas las respuestas, más dificultoso y caro resultará el plan de formación, pero también más eficaz. Acertar en cada caso la mejor relación posible entre eficacia y coste debe ser uno de los objetivos centrales del plan de formación. El empresario, tomado hasta ahora como el primer formando, pasaría acto seguido a ser el primer formador, inspirando cultural y estratégicamente el plan de formación de su empresa. Resulta preciso que la empresa se plantee sus necesidades de formación, pero, sobre todo, para establecer en paralelo su estrategia empresarial hacia la competitividad, lo que conllevaría también los niveles de integración y de participación necesarios. El sistema operativo de formación podría pasar así de ser un problema a convertirse en un instrumento poderoso de integración y de capacidad de respuesta; o de dificultosa barrera en posible trampolín. Finalmente, y desde un punto de vista operativo, el procedimiento interactivo de formación puede desarrollarse en ocho fases (prácticamente "talleres de trabajo") donde sean los propios participantes los que reconsideren sus necesidades de formación, a saber: 1. Participación generalizada. 2. Reinformación sobre los problemas de la empresa. 3. Reproyección de los fines empresariales. 4. Consenso de estrategias posibles. 5. Evaluación de primeros cambios. 6. Establecimiento de prioridades de formación. 7. Implementación del plan. 8. Evaluación de la formación. Fases con un tal contenido estratégico-empresarial que la formación obtenida se convierta en un subproducto positivo de la compleja operación de respuesta empresarial frente a los nuevos entornos. No es por nada que autores como Rosow y Zager (1990), Kubr y Prokopenko (1992) y Archier y Serieux (1985) fundamenten el desarrollo empresarial en el forzoso ayuntamiento Estrategia/Participación/Planificación/Formación. De donde puede enunciarse el quinto de los desafíos formativos: ningún empresario debería desconocer que la participación integrada del personal en los planes estratégico-formativos de la empresa puede resultar en la clave para su mejor adaptación al entorno.

\section{CONCLUSIONES}

Del enfoque crítico precedente cabe obtener algunas conclusiones que más bien se enuncian como nuevas hipótesis de trabajo: 1. La literatura científica que investiga los problemas empresariales no parece estar enfatizando suficientemente el peso específico que para la empresa representan conceptos como los de "sistemas de valores", "eficiencia organizacional» o "sistema suma no cero". 2. Ello implica consecuencias negativas para el desarrollo organizacional y se suele traducir en típicas lagunas formativas del $D E$. 3. El $D E$ que comenzara 
por no ser consciente de dicha laguna formativa se mostraría probablemente incapaz de cumplir el difícil rol empresarial que exige la siempre problemática adaptación al entorno. 4. La firme asunción por los $D E$ de los principios avanzados podría suponer un importante cambio empresarial con efectos positivos sobre la participación, la integración laboral, los conflictos laborales, el desarrollo de los RR.HH. y, finalmente, la competitividad y los beneficios. Se hace necesario, no obstante, continuar refinando teóricamente los conceptos presentados, al tiempo que resultaría altamente deseable que ello se llevara a cabo en procesos interactivos entre teóricos y prácticos donde los supuestos enseñantes aprendieran y los enseñados enseñaran, garantía suficiente de una adecuada formación participativa.

\section{BIBLIOGRAFIA}

Abramson, R., y Halset, W. (1979): «Planning for improved enterprise performance», Management Development Series, n. ${ }^{\circ}$ 15, ILO Pub., Geneve.

ARCHIER y SERIEUX (1985): La empresa del tercer tipo, Planeta.

ArgYris, C. (1974): The Applicability of Organizational Sociology, Cambridge University Press, New York.

BELASCO, A. J. (1992): Enseñar a bailar al elefante, Plaza y Janés, Barcelona.

Blau, P., y SCOTT, W. R. (1962): Formal Organizations, Chandler, San Francisco.

Bradley, K. (1995): Comunicación y Participación en las empresas: una realidad teorética y prácti$c a$, Cuenca Simposium.

Campbell, A., y Warner, M. (1988): «Strategic choice, organizational change and training policies", Journal of General Development.

CoOpnet, D. (1995): Human Resource Development for cooperative management..., Fifth progress report, work plan $95 / 96$.

Crozier, M. (1989): L'entreprise à l'ecoute. Apprendre le management post-industriel, Inter-Editions, París.

Denatt, R., y Jonhson, J. E. (1951): Negotiating with the Russians, World Peace Foundation, Boston.

DRUCKer, P. (1993): La sociedad poscapitalista, Apóstrofe, Barcelona.

ELSTER, J. (1991): Elemento de la sociedad, Gedisa, Barcelona.

EtzIoni, A. (1975): A Comparative Analysis of Complex Orgaizations, Ed. Free Press, New York.

GARMENDIA, J. A. (1994): Tres culturas $O+R H$, Editorial ESIC, Madrid.

Hall, B. P. (1994): Values Shift. A guide to personal \& organizational transformation, Twin Lights Pub., Rockport. MA.

Heller, W. (1965): Diccionario de Economía Política, Ed. Labor, S.A., Barcelona.

Herrán GASCÓN, A. (1993): La educación del siglo XXI, Editorial Ciencia 3, Madrid.

ILO (1974): Workers Participation in Decisions within undertakings, Oslo Symposium.

- (1977): Collective Bargaining in Industrialied countries, Recent Trend and Problems, Vienna Simposium.

- (1987): Current Approacher to collective Bargaining, Génova.

- (1992): «Entrepeneurship and Management Development», Newsletter, n. ${ }^{\circ} 1$.

- (1996): Global leadership conference: Management education and Training for sustainable development, UNEP Environment Programme.

KENNEDY et al. (1991): Cómo negociar con éxito, Deusto, Bilbao.

Kubr, M., y Prokopenko, J. (1992): Diagnosing management training and development needs, International Labour Office, Management development series 27, Geneva. 
LaX y Sobernius (1991): El directivo como negociador, Instituto de Estudios Fiscales, Ministerio Economía, Madrid.

Lazarsfeld, P., y Boudon, R. (1965): Le vocabulaire des sciences sociales, Ed. Mouton \& Co., Netherlands.

LEAVITT, H. J. (1988): Senderos corporativos. Cómo integrar visión y valores en las organizaciones, CECSA, México.

MalitZA, M. (1996): «Educación para el siglo XXI», Aprender para el futuro, Tema III, Fundación Santillana, Madrid.

March, J., y SimOn, H. (1981): Teoría de la Organización, Ed. Ariel, Barcelona.

MAYNTZ, R. (1967): Sociología de la Organización, Alianza Editorial, Madrid, 1972.

Montero de Burgos, J. L. (1990): Propiedad, Empresa y Sociedad, INAUCO, Madrid.

Nadler, L., y Nadler, Z. (1988): Developing Human Resources, Jossey-Bass Pub.

NASH, B. (1950): «The Bargaining Problem», Econometrics, 18.

- (1953): «Two persons cooperative games», Econometrics, 21.

Nash, B., y Zullo, A. (1989): Cómo hundir su empresa, guía práctica de la mala gestión, Ed. Temas de Hoy, S.A., Madrid.

PAUL, S. (1983): «Strategic management of development programmes», Management Development series, n. ${ }^{\circ} 19$, ILO, Geneve.

Parra Luna, F. (1975): Comparing National Social Performances, Ed. Imprimo, Geneve.

- (1977): Las organizaciones y sus sistemas de valores, Ed. Confederación Española de Cajas de Ahorros, Madrid.

- (1983): Elementos para una teoría formal del sistema social, Ed. Complutense.

- (1993a): El Balance Integrado de la Gestión Estratégica, Ed. Deusto, Bilbao.

- (1993b): La empresa contra si misma, Deusto, Bilbao.

- (1995): Social autopoisesis. A quantitiative approach, ed. Keith Ellis et al., Plenum Press, Nueva York.

PARsons, T. (1960): Structure and Process in Modern Societies, Free Press, Nueva York.

Perrow, Ch. (1961): "Goals in Complex Orgaizations», American Sociological Review 26, n. ${ }^{\circ}$ 6, pp. 854-865.

- (1963): "Goals and Power Structures», The Hospital in Modern Society, Freidson Eliot ed., Nueva York.

- (1968): «Organizational Goals», International Encyclopedia of the Social Sciences, ed. vol. 11, Macmillan, Nueva York, pp. 305-311.

- (1990): Sociología de las organizaciones, Ed. McGraw-Hill, Madrid.

Plessis, J. C. (1984): Concevoir et gerger la formation dans l'entreprise, Ed. Les editions d'organization, París.

Pruit, D. G. (1981): Negotiation Behavior, Academic Press, Nueva York.

PÜmpin, C., y García EChevarría, S. (1990): Dinámica empresarial. Una nueva cultura para el éxito empresarial, Díaz Santos, Madrid.

Rosow, J. M., y ZAGER, R. (1990): New roles for managers. Manager as trainer, coach and leader. Creatring a high-performance management team: eastman kodak's 13 room, ed. Workin America Institute Inc., Nueva York.

SCHEIN, L. (1988): La cultura empresarial y el liderazgo, Plaza y Janés, Barcelona.

SEOANE, J. (1994): «Reevaluación del concepto de organización», en A. RoDRíGUEZ, Las organizaciones a debate, Ed. Universidad de Granada, Granada.

TOUZARD, H. (1981): La mediación y la solución de los conflictos, Herder, Barcelona.

Van Gigh, J. P. (1978): Applied General systems theory, Harper and Row Publishers, Nueva York.

Wall, J. A. (1985): Negotiation Theory and Practice, Scott, Foreman and Co., Glenviwe, Ill. 


\title{
PALABRAS CLAVE
}

- Sistema de Valores.

- Concepto axiológico de empresa.

- Eficiencia organizacional.

- Entorno.

- Sistema "suma no cero".

- Negociación.

- Plan Estratégico y Formación.

\section{KEYS WORDS}

— System of values.

- Axiological company concept.

- Organisational efficiency.

- Environment.

— «Non zero sum» system.

- Negotiation.

- Strategic Training Plan.

\begin{abstract}
From a critical perspective, this paper attempts to demonstrate that relevant organisational theories have not yet been incorporated in basic management curricula. It also points to the traditional communication gap that still exists between universities and companies. The theoretical approaches that would be embraced in this conceptual shortfall include the axiological concept of companies (which assumes that they are limited to producing complex systems of values); the definition and calculation of entrepreneurial efficiency (or the relationship between the values produced and the means used); the concept of the environment to which companies must adapt themselves (analysis of social, economic, cultural and other changes); the concept of the company as a "non zero sum system» (which would give rise to synergetic as opposed to homeostatic bargaining processes); and finally, the design of a training concept to complement strategic company plans in response to the challenges of the environment. The paper ends with a description of an eight-phase training process that forms part of the global corporate strategy, called the «Strategic-Participative Training Plan».
\end{abstract}

